\title{
The Impact of Terrorism on Cycle Times in International Supply Chains
}

\author{
Shams Rahman* \\ Christopher Findlay**
}

\begin{abstract}
Supply chains in East Asia are being redesigned following the reassessment of the risk of disruption through terrorist attacks. The nature of these risks and of the costs of the private sector responses is reviewed. The research available suggests the costs incurred are substantial. Government regulation applied to security matters also applies within supply chains. It too has been redesigned in response to the change in the risk of terrorist attacks. Examples of its impacts, and its costs and benefits, are presented. Relevant empirical work remains scarce, but principles for government's role can be identified.
\end{abstract}

\section{INTRODUCTION}

To date many studies have been conducted to identify critical success factors in supply chain management (Power et al., 2001; Homes, 1995), assess the impact of TQM practices on logistics and supply chain performance (Tan et al., 1997, Anderson et al., 1998), examine the role of communication in supply chain management (Ellinger et al., 1999), and investigate the impact of information technology on supply chain capability (Cross et al., 1997). A few attempts have been made to assess the impact of cycle time reduction in supply chains (Frolick, 1996; Nicholas Jr. et al., 1995), and global trade risks in terms of exchange rate risk and operating exposure risk (Kogut and Kulatilaka, 1996) but no studies have examined the effect of terrorism risk on the performance of international supply chains.

The study is prompted by the increasing concern about the impact of disruption to supply chains due to the terrorist attacks. This concern has been prompted by the attack of September 11, 2001 and by the Bali bombing, amongst others. It is illustrated by the considerable attention given to cooperation on anti-terrorism strategies at the APEC Leaders meetings in Bangkok in September 2003. They expressed their concern about the threat of 'transnational terrorism' and they committed themselves to a number of counter-terrorism measures.

At their previous meeting in Mexico in 2002 the APEC Leaders had also proposed to protect cargo by implementing a cargo security regime, implementing common standards for electronic customs reporting, promoting 'private-sector adoption of high standards of supply chain security, as developed by the private sector and law enforcement officials', and promoting ship and port security.

\footnotetext{
* Professor, Institute of Transport Studies, School of Business, The University of Sydney, Sydney, NSW Australia

** Professor, Asia Pacific School of Economics and Government, The Australian National University, ACT, Australia
} 
APEC has already started work on these commitments (APEC, 2003; Porter, 2003). A framework in which the issues of cycle time and other performance indicators can be considered is developed. The focus here is on the supply chain, its characteristics and how management of supply chains has responded to the threat of terrorism. The nature of the supply chain and its management are introduced in the next section. Costs incurred as the private sector adjusts its supply chain are discussed. Governments also regulate activity at various points in the supply chain, and that regulation is becoming more intense as a result of the reassessment of the risk of terrorism. The rationale for and impact of government policies in the supply chain are also reviewed here.

\section{THE SUPPLY CHAIN CONCEPT}

The supply chain involves the provision of a variety of services which link the original producer of a good and its final consumer. International supply chain management is a set of approaches utilised to integrate all the actors involved, including suppliers, producers, warehouses, customs, stores, and customers. The aim is to build a supply chain to minimise system-wide costs while satisfying service level requirements, including mechanisms so that merchandise is produced and distributed at the right quantities, to the right locations and at the right time (Simchi-Levi et al., 2000).

Figure 1 provides an illustration of an international supply chain. The objective of the supply chain management is to be efficient across the entire chain. Thus the emphasis is not on simply minimising transportation cost or reducing inventories, but on taking a systems approach to decision making.

Figure 1. A generic international supply chain network

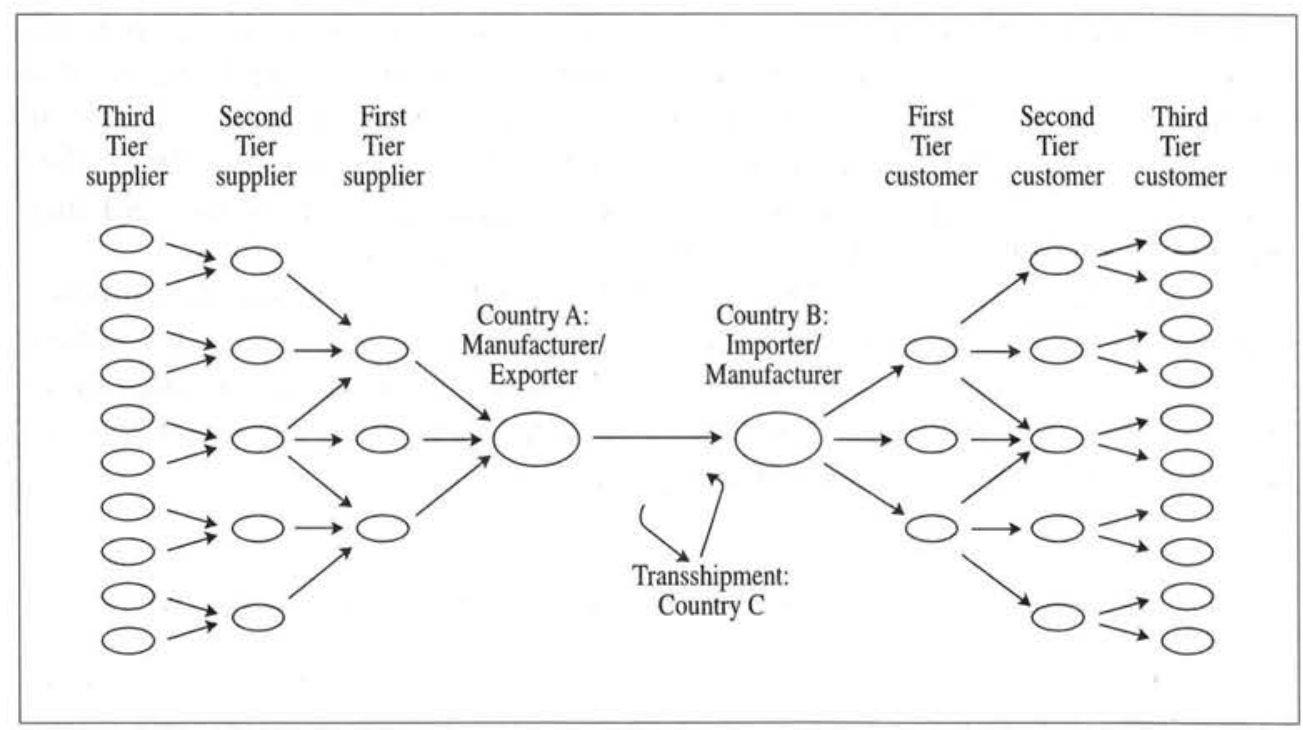


In international settings not all chains will use the same procedures or technologies - there will be differences depending relative costs of labour and capital, including access to skilled labour (Wood et al., 1995; Fernie, 1995). Some chains will appear to be relatively labour intensive, depending on the locations which are involved. But all would be expected to work to the objective just outlined. On the other hand, not all will meet will necessarily be performing at lowest possible costs, perhaps because of procedures or constraints imposed by governments.

Different products may demand different characteristics in their supply chains. An obvious example is the sort of products which move via express freight for which time is critical. For other lower unit value items, transport cost may take a greater weight in decision making about the design of the supply chain.

\section{SUPPLY CHAIN CHARACTERISTICS}

It had always been a challenge for the business to meet demand with supply. The higher the mismatch between demand and supply, the greater is the cost of managing supply chains. There are three different types of situation that can be used to characterise the nature of the supply chain. These are classified by the certainty with which information is known about supply and demand. These are (Rahman, 2003);

- Demand certain-supply uncertain: the case of just-in-case

- Demand uncertain-supply certain: the case of just-in-time

- Demand uncertain-supply uncertain: the case of just-in-case.

Demand certain-supply uncertain: a case of just-in-case: In the three decades up to and including the 1970 s, the situation can be classified as 'demand certain and supply uncertain' (Rahman, 2003). There were relatively long product cycles and low levels of product variety. Demand in terms of volume and preferences for product features changed relatively slowly. The more important uncertainties related to the ability to supply. So inventory holdings were high and goods were held 'just-in-case' products failed to arrive.

Demand uncertain-supply certain: the case of just-in-time: Market characteristics changed in the 1980s and 1990s. Variety of products widened, and product life cycles shortened. Customers demanded high quality products and services in shorter delivery time. Thus demand became less certain relative to the capacity to manage supply. In this situation supply was managed through customisation applying the principles of just-in-time. Over the 1990 s, the management of the supply chain continued to evolve in this environment. New players emerged such as the independent providers of supply chain management services. Firms contracted out these services to third parties and more recently those parties themselves were contracting out large parts of their own operations.

Demand uncertain-supply uncertain: the case of just-in-case: The shock to this evolution has been the introduction of new uncertainties on the supply side. Markets are now operating in a situation of both demand uncertain and supply uncertain, a consequence of the impact of the risk of disruption associated with terrorism and other factors, including SARS. 
Thus the nature of supply chain has shifted from the 60 s and 70 s situation of 'justin-case' to the 2000 s situation of 'just-in-case' through the 'just-in-time' situation. However, the difference is that the 'just-in-case' situation of $60 \mathrm{~s}$ and $70 \mathrm{~s}$ was characterised by demand certainty and supply uncertainly, whereas, the 'just-in-case' situation of the 2000 s is characterised by both demand uncertain and supply uncertain.

The change in the environment of the supply chain is illustrated in Figure 2. A later section examines the nature of costs in the supply chain and the ways in which government policy affects those costs. The next section discusses in more detail the impact of the threat of terrorism on the supply chain.

Figure 2. Characteristics of supply chains over time

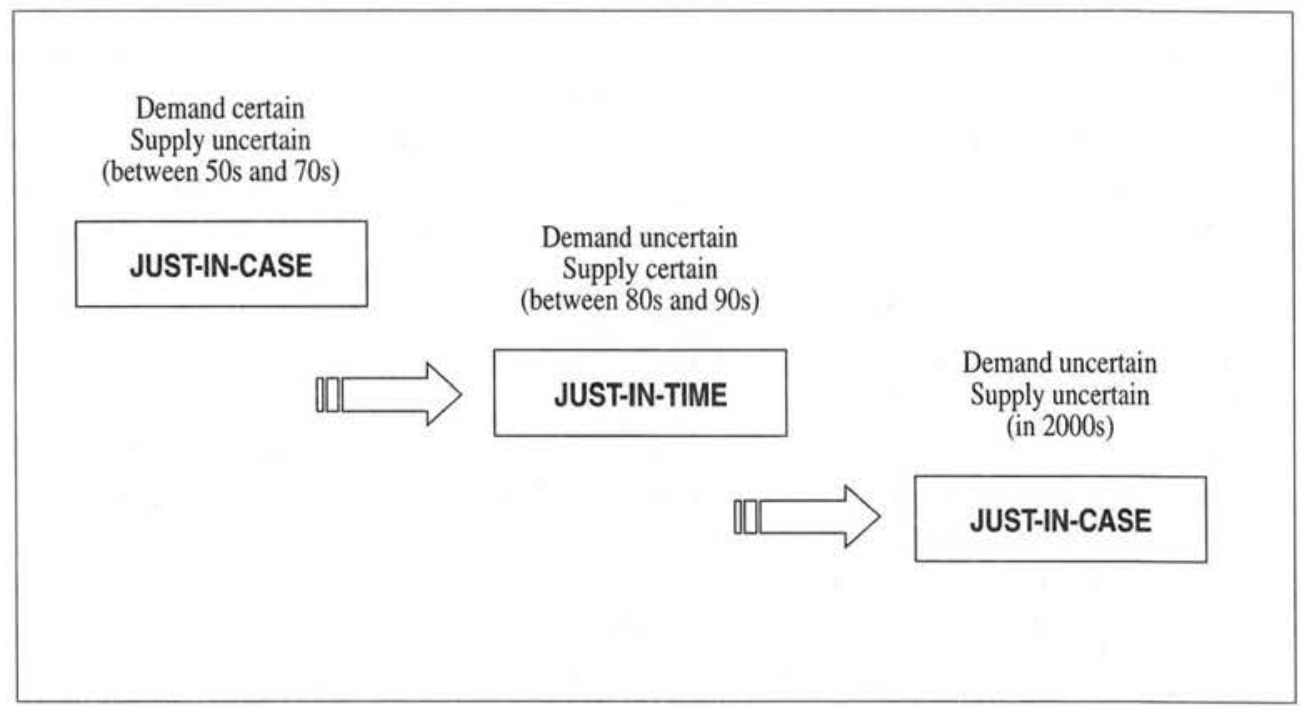

IV. THE THREAT OF TERRORISM

\section{Impact on investment and growth}

The effect of the threat of terrorism is illustrated in Figure 3. The threat involves two dimensions; one actual acts of terrorism and the other the perceived risk of such an action. 
Figure 3. Effects of Terrorism

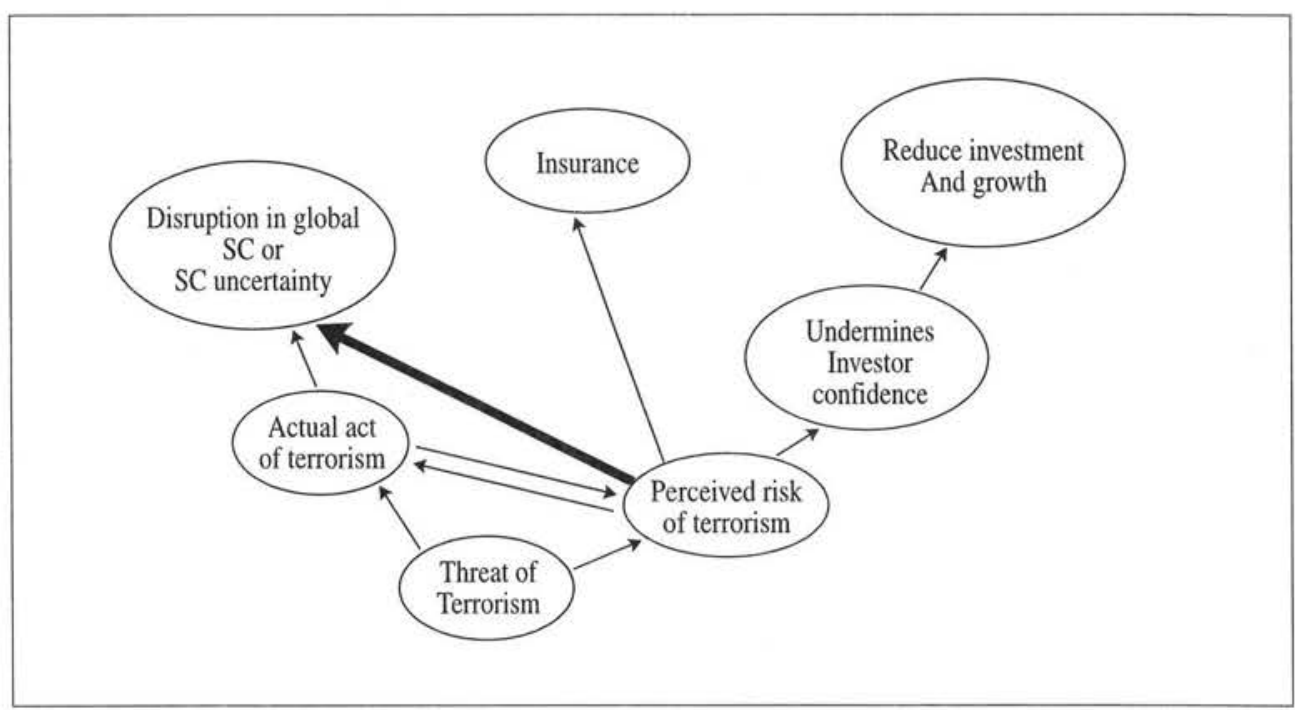

Source: Rahman (2003)

There are immediate losses from a terrorist attack, including the loss of life, of transport vehicles and infrastructure. Various studies have examined the effects of a shut-down of key infrastructure components as a consequence of an attack, including those of delay, diversion of traffic and loss of economic activity. The Conference Board with Booz Allen Hamilton, as quoted by the OECD (2002) simulated the effect of widespread port closures in the US and estimated the cost at \$US58b over the 92 day simulation period. Other effects reflected in Figure 3 include those on investor confidence and on economic growth (Walkenhorst and Dihel 2002, Rahman, 2003). Business might cover itself against the risk of disruption from terrorist attack by taking out insurance. However, the greater risk has also had a significant effect on insurance markets, including the size of premiums for relevant insurance, and even the willingness of companies to offer insurance. Business then had more incentive manage the risk themselves, rather than pass it off to others.

The OECD (2002), however, concludes in its review of work on the costs of terrorism that the direct costs are likely to be much smaller than the costs associated with the indirect effects and with the responses to the change in perceptions of risk as a result of the attacks. These indirect costs are our main interest here. The link between the perceived risk of terrorism and supply chain uncertainty is highlighted in Figure 3. That link is our focus here. We proceed with that discussion by reviewing some key indicators of supply chain performance.

\section{Impact on supply chain performance}

Appropriate metrics for today's global competition measure more than traditional productivity indicators and include utilisation and performance indicators. 
The performance measures for supply chains can be classified into three broad categories (Dornier et al., 1998);

- Quality - The key goal here is customer satisfaction and the question is whether supply chains are geared to and capable of producing it.

- Timeliness - Many aspects of supply chain have deadliness, and logistics activities also affect the ability of other parts of the supply chains to meet their time-related goals.

- Productivity - The productivity of resources activated affects the costs of delivery.Some of the main performance metrics which belong to the three broad categories are fill rate, on-time delivery, perfect order fulfilment, inventory, and cycle time (Lee and Billington, 1992; Beamon, 1999; Rahman, 2002).

Figure 4. Terrorism and Supply Chain Management

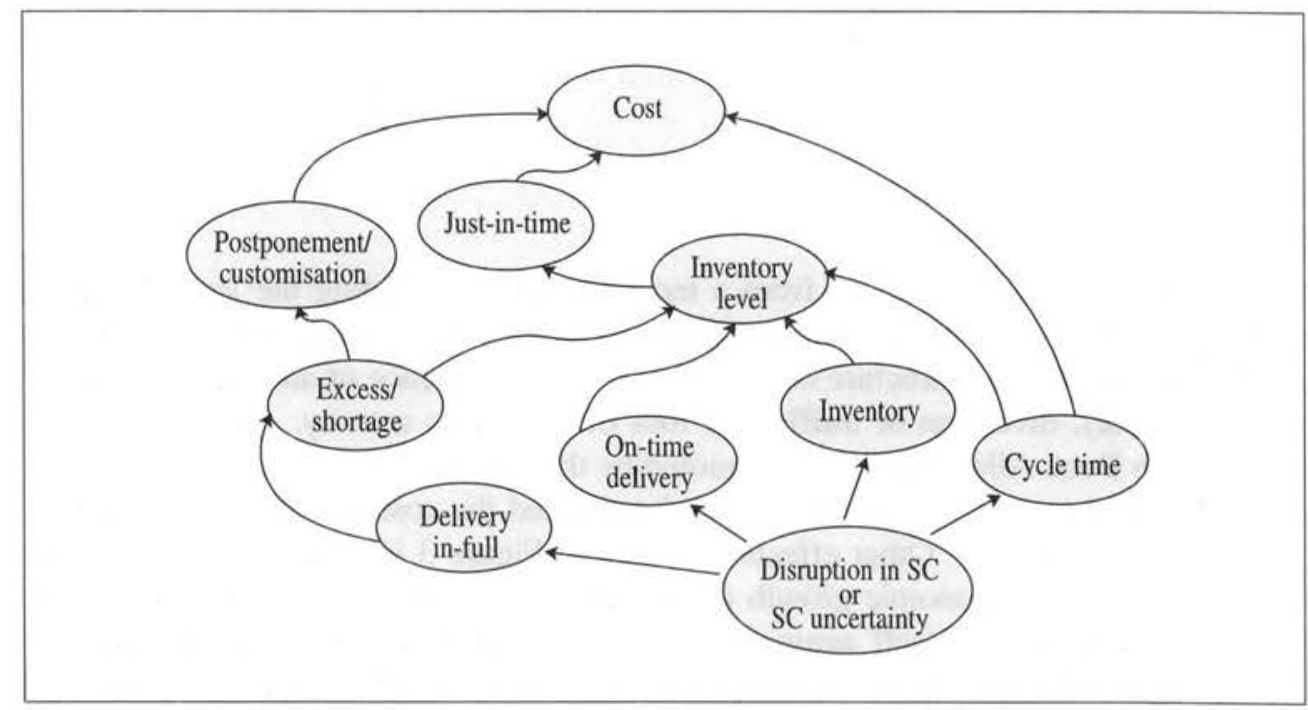

Source: Rahman (2003)

With this background we can identify the effects of the risks of disruption, and of the responses to changes in those risks, on supply chain performance. These effects are illustrated in Figure 4. The private sector could respond in a number of ways to the risk of disruption and there are trade-offs between them.Consider first the range of possible responses by firms in which they make choices using their current technologies for supply chain management. To avoid the risks of disruption, firms might redesign their supply chains or duplicate them, running smaller volumes through each chain. Business might also introduce their own procedures for inspecting cargo or establishing its security.

Relying heavily on a single source for the supply of product and parts leaves a company highly vulnerable to prolonged and expensive supply gaps. Although it could be less preferred and more expensive, companies will cultivate alternative sourcing arrangements. 
Compaq Computer, for instance, has assembly plants in Europe, Asia, and North and South American countries. If political strife affects one region, Compaq can quickly shift production elsewhere. It also has secondary suppliers for critical parts and foreign suppliers have secondary facilities within the United States (Martha and Subbakrishna, 2002).

In the original situation, supply chains are expected to have been designed to minimise the costs of reaching a particular service standard. When the chain is then redesigned through locations where it is expected the risks of disruption is lower, higher costs will be incurred. These costs can be interpreted as a premium paid for lower risk.

Cycle time is the elapsed time between customer enquiry and customer need being met. It has been shown to be a fundamental driver in achieving enhanced business performance (Thomas, 1990; Beamon, 1999; Rahman, 2002). Disruptions in supply chains obviously make the cycle time longer. Both re-routing supply and adding new time-consuming procedures to the existing chains will also add to cycle time.

Through its direct and indirect effect on inventory level, on-time delivery, JT, and postponement/ customisation policies, cycle time will have a profound effect on quality (customer satisfaction), timeliness of service, and productivity. For instance, a supply chain with longer cycle time (than necessary) will merely activate more resources but will not utilise them. This will have an impact on the leanness of supply chains and thus will affect the productivity. This conclusion is supported by the results of the large-scale industrial survey undertaken by Schmenner (1988). It shows that the only significant factor in improving productivity is to re-engineer supply chain operations so as to reduce cycle time.

Research in supply chain performance shows that 'consistency of delivery' and 'speed of delivery' are the two most important performance measures (Marr, 1994; Jackson, Keith and Burdick, 1986). Longer cycle times will affect both these measures of performance and, in turn, will affect timeliness of delivery. Additional costs from poor productivity and inconsistency of delivery will reduce the customer satisfaction level. As a consequence, there might also be lower degrees of customisation, and the rate of complete order fulfilment might suffer. A further consequence is that just-in-time systems may become less effective. Pioneered by the Toyota Automotive Company, the just-in-time principle calls for products and components to deliver and arrive exactly when they are needed.

The OECD (2002) reports that 'prior to the terrorist attacks, estimates of the costs of time delays, meaning an increase in cycle time, paperwork and compliance related to border crossing ranged from 5 to 13 percent of the value of the goods involved' (p. 10). The OECD also quotes work by Hummel that the cost of a delay in moving goods across borders is equivalent to an extra ad valorem tariff of 0.5 percent for every day of delay.

Firms also respond to higher variability in the time for goods to be delivered by holding higher levels of inventory. These effects on inventory can be significant. The OECD (2003) reports the results of a study which reported in that in 2001 large US companies on average held 1.36 months of inventory, compared to 1.57 months in the early 1990 s. 
The study projects that inventory levels will rise in 2002 to 1.43 months in response to uncertainty in supply chains, that is, as companies move towards a 'just in case' approach to inventory holding. The contribution of this change to business costs in that year is estimated to be \$US50b to \$US80b. That cost would remove 'approximately half of the logistics productivity gains realised in the United States over the last 10 years' (p. 18).

Instead of suffering higher costs through higher inventories, the use of less preferred chains, or lower performance, firms might invest themselves to increase the security of their cargo. An example would be invest in new inspection technology (such as x-ray machines) or the introduction of a container monitoring system. We discuss further below some examples of technological change which have the additional advantage of being sanctioned by governments and therefore are able to reduce the costs of compliance with government regulation.

\section{Distribution of higher costs}

Costs of the type just reviewed will be distributed along the supply chain, and most likely eventually be borne by both final consumes and original producers. The origin of the risk and the location of the expenditure incurred in reaction to the risk is not relevant. They could occur at the start, middle or end of the supply chain. But the response to that risk incurs a cost, as just discussed, and market processes will redistribute cost, most likely to either end of the chain. Producers bear a cost even though the perception of the risk might arise in consuming countries. Consumers would bear a risk even though the origin of the threat lies in a producing country.

The private sector will invest in procedures and technologies that reduce the impact of disruption on their own business. They have a strong incentive to do so, when a terrorist attack has not only short-term costs but when it could also have long term effects through customer recollection of firms' association with the event. But will the private sector response be sufficient from society's point of view? Most likely it will not. There are other actors in the supply chain who would also bear costs in the face of supply chain disruptions. Private business will choose solutions and invest in those solutions to a degree that yields a positive return in their business, given the new environment. They will not take into account the benefits of those investments to other actors in the chain. For that reason, their investment from a social point of view may not be sufficient.

Governments in this situation have role in encouraging private investors to take these spillover effects into account. Governments intervene to do so in various ways and their choices also affect supply chain performance. Here we focus on governments' regulatory responses, for example, requirements in terms of reporting information and inspections by officials. These are activities designed to reduce the risk of terrorist attack. However as discussed in the next section they also impose costs along the supply chain.

There is a question about the most efficient location in the supply chain to establish new security measures. Governments, and their citizens, at the end of the supply chains may be the target of planned attack. 
But the materials for the attack might be compiled at an earlier point in the chain, for example, during container loading. Most likely, but not necessarily, attention to security is also implemented more efficiently at earlier points in the supply chain rather at the location of the planned attack. The design and implementation of new regulation is done best cooperatively rather than unilaterally in this situation. Governments responsible for potential targets therefore have a strong interest in cooperating with governments responsible for infrastructure at earlier points in the supply chain.

\section{Impact of government policy on supply chain performance}

Government policy has a number of effects on the cost of delivery through both its charges (a relatively small part of the cost of delivery) and the procedures which it imposes on the chain (see OECD (2003) for an assessment of new measures relating to shipping and ports). Of course, these procedures are also supposed to reduce risks in the chain. They will affect the time taken to move through the various activities involved, in customs or quarantine for example. These add to cycle time with the sorts of effects already discussed.

Costs are not only associated with delays due to inspection and other processing procedures. New requirements are being imposed in advance of shipment. For example, the US Customs Service has also introduced a 24-Hour Advance Cargo Manifest Rule. Cargo manifests must be provided electronically 24 hours before loading a container bound for a US port. The World Bank (2003) for example refers to extra costs likely to be associated with the 24 hour rule, including the costs of documentation. There is also reference to the relatively large burden these procedures place on small to medium enterprises. The World Bank also points out the difficulties created for some fresh produce which previously had not been picked for longer than 24 hours prior to departure. The rule makes the handling of emergency replacement parts or medical suppliers more complex.

\section{Offsetting benefits}

Investments undertaken by the private sector at their own initiative or mandated by governments can generate offsetting benefits. Technology might be adopted which facilitates the monitoring of cargo, such as the use of RFID tags on containers along with readers located at various points along the supply chain. The information this technology provides can reduce waste as well as the costs of pilfering and loss of containers. Container tracking systems also help plan the use of containers and reduce the requirements for inventories of containers.

Benefits are greater when the monitoring systems can be linked to each other. Currently different information systems may be used at different points in or sectors of the supply chain. Compiling and analyzing data from different sources can be costly (Bearing Point, 2003).

Use of technologies which can either communicate with each other, or using the same technology for monitoring reduces these costs. 
Bearing Point (2003) also points to the benefits of coordination of the adoption of this technology, since as it is applied to an increasing number of nodes in a network, new links can be added at lower cost. Further, if a particular technology and the information it provides is endorsed by governments, its adopters may benefit from reductions in the cost of compliance with regulatory requirements, for example, inspection times or expenses.

An example of government cooperation with business to reduce the burden of regulation is the United States Customs Service's Custom-Trade Partnership Against Terrorism (C-TPAT) and Container Security Initiative (CSI). These are voluntary programs aimed at improving ship, port and container security. Companies that will participate in these programs must conduct a self-assessment of their supply chains' security using guidelines developed by the US Customs. The main advantage to the participating companies is that their containers are less likely to be detained by US Customs for detailed inspection. This will also motivate companies to invest in security systems.

\section{Evaluating government policy}

With respect to the security agenda, at least to date, governments have adopted a set of specific measures in response to their understanding of the new situation and their assessment of the risks involved. These initiatives are built on the target of achieving an acceptable level of risk.

The change in the threat of terrorism raises issues similar to those in other forms of 'import risk analysis' in which policy responses are evaluated using the criterion of cost effectiveness. This involves 'an evaluation of the costs of different measures in addressing a particular benefit. A measure is chosen on the basis that it involves the least aggregated cost.' (Binder, 2002, p. xvi). This approach takes as given the target in terms of risk reduction but then stresses the value of finding the least cost methods for achieving that target.

An even more extensive approach would be to apply a cost-benefit analysis of the measures proposed. The trade-off between the reduction in risk and the cost of the measure is then also examined. This approach involves identifying and measuring the costs as well as benefits of a measure that reduces risk to particular community groups, relative to a situation of the absence of any measure; determining the extent of net benefits (or net costs) to the community as a whole from such a measure, allowing for private sector responses and effects; ranking the measure against alternatives, according to the magnitude of net benefit; and choosing the measure with the highest net benefit to the community as a whole (Binder, 2002).

Regulation is not the only form in which governments might intervene. Activities that generate positive spillovers often attract subsidies, in this case, subsidies for initiatives or investments that reduce the risk of attack. The advantage of this approach is that the provision of subsidies can be made open to a competitive process, which will facilitate the development of innovative and lower cost solutions. The cost benefit analysis just outline would include consideration of such measures. 
A complete cost benefit analysis is demanding. Applying, at least, the cost effectiveness methodology to government initiatives would be valuable. Undertaking transparent assessments of the costs of various measures adopted so far would contribute to that goal. Establishing institutional arrangements in which alternative and innovative measures that achieve the same risk reduction target can be identified is a complement to that work. Not only might new measures emerge, especially as technology changes, but also the procedures and methods adopted might also vary, on cost effectiveness grounds, between points of origin in the supply chains. Access to innovation in these various ways will also be critical to capturing the side benefits which were discussed in the previous section.

\section{CONCLUSION}

We have noted the likely reactions of the private sector to the risk of disruption to supply associated with terrorism, and the costs of and trade-offs involved in their reactions. We reviewed the case for government intervention in this decision making and its likely impacts, not only on the costs within the chain but also the possibility of additional benefits from private sector initiatives to meet the government requirements. However, we also stressed the value of a thorough cost benefit analysis of government regulation and if not that then at least a cost effectiveness study. The work by Bearing Point (2003) is an example of an evaluation of a strategy for reducing the cost of compliance.

In this conclusion we add comments on the value of international cooperation along the supply chain to reduce the costs of reducing the risk of disruption. Cooperation could be organised commercially through foreign investment or other forms of trade in services. Whether these forms of cooperation are possible depends on the openness of the relevant markets. For example, open markets for logistics services transfers the technology for the redesign and management of integrated services is likely to have significant effects on the cost of delivery. The composition of those costs might change, for example, the contribution by management fees will increases, but this change will be compensated for by reductions in other items, not necessarily in the transport component but more likely in the costs associated with damage, losses and inventory. Globally competitive firms will be able to provide the component services in more open markets, but in many countries restrictions remain on foreign participation in these markets.

Cooperation could be driven by policy. Higher costs along the chain whatever their source are a problem for everyone. However, the significance of those costs will vary between economies and given the different stages of development, economies differ in their capacity to contribute to efforts to reduce those costs. Governments may support the transfer of technology for increasing supply chain security among their trading partners. There are instances as noted in the paper where cooperation between governments is required to find efficient solutions to the problem of reducing the risk of terrorist attack. 
The side benefit to the technology provider is that higher levels of security upstream in the supply chain, and the application of compatible technology, reduce the cost of responding to risks downstream. The design of these arrangements, like the work on cost benefit analysis of regulatory policy, and of alternates such as the provision of subsidies through competitive tendering, are topics for further work.

\section{REFERENCES}

Anderson, R. D., Jerman, R. E., and Crum, M. R. (1998) “Quality management influences on logistics performance”, Transport Research Part E, 34, 2, 137-148.

APEC (2003) 'Report to SOM Chair on Outcomes of the STAR Conference', Counter-Terrorism Task Force Meeting, Khon Kaen, May 26.

Beamon, B. M. (1999) "Measuring supply chain performance", International Journal of Operations and Production Management, 19, 3, 275-295.

Cross, D.J., Goldsby, T. and Clinton, S. R. (1997) "Information technology influences on world class logistics capability”, International Journal of Physical Distribution \& Logistics Management, 27, 1, 4-17.

Dornier, P, Ernest, R, Fender, M, and Kouvelis, P (1998) Global Operations and Logistics - Text and Cases, John Wiley \& Sons, Inc. NY.

Ellinger, A. E., Daugherty, P. J. and Plair, Q. J. (1999) "Customer satisfaction and loyalty in supply chain: the role of communication", Transport Research Part E, 35, 121-134.

Fernie, J. (1995) "International comparisons of supply chain management in grocery retailing”, Service Industries Journal, 15, 134-147.

Forrester, J (1958) "Industrial dynamics: a major breakthrough for decision makers", Harvard Business Review, July-August, 37-66.

Forrester, J (1961), Industrial Dynamics, MIT Press, Cambridge, MA.

Frolick, M. N. (1996) "Cycle time reduction in the order processing of packaged computer software”, Cycle Time Research, 2, 2, 81-87.

Gibson, Ken (2001) "Analysing the trends: predicting the future of logistics in Asia" presentation to the conference on "Toward the final frontier: logistics and the efficient supply chain", 27 September.

Hertel, T., T. Walmsley, and K. Ikatura. (2001) "Dynamic Effects of the 'New Age' Free Trade Agreement between Japan and Singapore." Journal of Economic Integration 24: 1019-49.

Holmes, G (1995), Supply Chain management: Europe's New Competitive Battleground, EIU Research Report.

Jackson, D. W., Keith, J. E. and Burdick, R. K. (1986) "Examining the relative importance of physical distribution service elements", Journal of Business Logistics, 7, 2, 14-32.

Kogut, B and Kulatilaka, N (1996) "Operating flexibility, global manufacturing and option value of a multinational network”, Management Science, 40, 1, 123-139.

Lee H. L. and Billington C. (1992) "Managing supply chain inventory; pitfalls and opportunities”, Sloan Management Review, 33, 65-73. 
Lim, Irvin (2002) "Not yet all aboard... but already all at sea over container security initiative”, Working Paper No. 35, Institute of Defence and Strategic Studies, Singapore, October.

Marr, N. E. (1994) "Do managers really know what service their customers require?", International Journal of Physical Distribution \& Logistics Management, 24, 4, 24-31.

Martha, J and Subbakrishna, S (2002) "Targeting a just-in-case supply chain for the inevitable next disaster", Supply Chain Management Review, 6, 5, 18-23.

Nicholas, Jr. E. L., Frolick, M. N., and Wetherbe, J. C. (1995) "Cycle time reduction: an interorganisational supply chain perspective", Cycle Time Research, 1, 1, 63-84.

OECD (2002) The Impact of the Terrorist Attacks of 11 September 2001 on International Trading and Transport Activities, Working Paper of the Trade Committee, Trade Directorate, OECD, Paris, March.

OECD (2003) Security in Maritime Transport: Risk Factors and Economic Impact, Maritime Transport Committee, Directorate for Science, Technology and Industry, OECD, Paris, July.

Porter, I. W (ed) (2003) Proceedings of the Symposium of Maritime Experts to Assist in Implementation of the Secure Trade in the APEC Region (STAR) Initiative, Australian APEC Study Centre, Monash University.

Power, D, Sohal, A. S., Rahman, S (2001) "Critical success factors in agile supply chain management: an empirical study", International Journal of Physical Distribution \& Logistics management, 31, 4, 247-265.

Rahman, S. (2002) "The theory of constraints' thinking process approach to developing strategies in supply chains", International Journal of Physical Distribution \& Logistics Management, 32, 10, 809-828.

Rahman, S. (2003) "Costs and Impacts of Maritime Security Measures on Global Supply Chains", presentation to the CSCAP Maritime Cooperation Working Group/PECC Meeting, Manila, 6-7 September.

Schmenner, R. W. (1988) "The merit of making things fast", Sloan Management Review, 11-17.

Simchi-Levi, D, Kaminsky, P and Simchi-Levi, E (2000) Designing and Managing Supply chain-Concepts, Strategies, and Case Studies, Irwin McGraw-Hill, USA.

Tan, K, Kannan, V R, Handfield, R B and Ghosh, S (1999) "Supply chain management: an empirical study of its impact on performance", International Journal of Operations and Production Management, 19, 10, 1034-1052.

Thomas, P. R. (1990) Competitiveness Through Total Cycle Time, McGraw-Hill, NY.

Walkenhorst, Peter and Nora Dihel (2002) "Trade impacts of the terrorist attacks of 11 September 2001: A quantitative assessment”, paper prepared for the Workshop on the Economic Consequences of Global Terrorism, Berlin, June.

Wood, D, Barone, A, Murphy, P., Wardlow, D., International Logistics, Chapman \& Hall, NY

World Bank, "Reducing Trading Costs in a New Era of Security", chapter 5 in World Bank, Global Economic Prospects 2004, World Bank, Washington. 